\title{
COST ANALYSIS OF SEAWATER DESALINATION USING AN INTEGRATED REVERSE OSMOSIS SYSTEM ON A CRUISE SHIP
}

\author{
GULER E. ${ }^{1}$ \\ ONKAL ENGIN G. ${ }^{2, *}$ \\ CELEN M. ${ }^{1}$ \\ SARI ERKAN H. ${ }^{2}$
}

\author{
${ }^{1}$ Gebze Technical University, Department of Environmental Engineering \\ Gebze, 41400 Kocaeli, Turkey \\ ${ }^{2}$ Yildiz Technical University, Faculty of Civil Engineering \\ Department of Environmental Engineering, Esenler, 34220 Istanbul, Turkey
}

Received: 29/12/2014

Accepted: 06/03/2015

Available online: 13/05/2015 *to whom all correspondence should be addressed: e-mail: gengin@yildiz.edu.tr

\section{ABSTRACT}

The best method to treat seawater is known to be the use of reverse osmosis (RO) systems. The cost factor becomes the most important issue when using RO systems. Although quite costly, RO systems are essential systems for ships. As known very well, water is a critical resource on ships, especially the ones serving quite a large number of passengers. In this study, therefore, RO system capability under different conditions together with cost analysis was examined on a relatively small cruise ship. The system used had a daily water treatment capacity of $30 \mathrm{~m}^{3}$. The RO system was composed of a sand filter, a cartridge filter, four pieces of membrane filter modules and a mineral filter. During the study, samples from the Black Sea, the Aegean Sea and the Mediterranean Sea, which have different physical and chemical properties, were examined from the quality point of view. A comprehensive cost analysis was also performed in order to determine the feasibility of the system for the production of potable water for a cruise ship.

Key Words: Reverse Osmosis, Seawater, Potable Water, Cost Analysis

\section{Introduction}

Reverse Osmosis (RO) is one of the membrane processes, in which seawater is filtered through a high pressure membrane to remove salts and other impurities to produce water suitable for drinking. This system is used on most ocean-going vessels including cruise ships and navy vessels. However, wide-spread implementation of seawater desalination technology is currently limited by complex environmental and economic factors (Greenle et al., 2009; Shaffer et al., 2012). In general, desalination technologies can be classified in two different mechanisms, namely, thermal and membrane-based desalination. Although both technologies find an application area, the RO membrane desalination is the primary choice with a capacity of up to $44 \%$ of the total world desalination capacity (Greenle et al., 2009; Misdan et al., 2012).

As well known, the major energy requirement for desalination is the seawater pressurization (Khawaji et al., 2008). Pre-treatment is generally needed to eliminate the impurities in seawater, which might increase membrane fouling. The type of pre-treatment to be used largely depends on the feed water characteristics, recovery ratio, and product water quality (Al-Sheikh, 1997; Bou-Hamad et al., 1997; Durham and Walton, 1999; Khawaji et al., 2008). In post-treatment, permeate is generally re-mineralised and/or re-hardened in order to adjust to drinking water standards (Fritzmann et al., 2007; Khawaji et al., 2008). 
The cost of a reverse osmosis plant depends on the type of feed water, plant size, energy source, and pretreatment method. The difference between applied pressures required to treat these types of water is due to varying salt concentrations. Plant size is another important effect for cost calculation. It was reported that smaller plants (less than $5000 \mathrm{~m}^{3} /$ day) tend to be more expensive per unit water processed than medium sized (5000-60.000 $\mathrm{m}^{3} /$ day) or large (over $60.000 \mathrm{~m}^{3} /$ day) plants (Moran et al., 2010). The cost per $\mathrm{m}^{3}$ of water was reduced dramatically over the years from about $\$ 5.00$ in 1970 s to $\$ 1-2$ per $\mathrm{m}^{3}$, in 1990s (Greenlee et al., 2009). It was reported that operational and maintenance costs constitute about $50 \%$ of the total costs, in a typical seawater desalination system (Moran et al., 2010).

Although quite costly, RO systems are essential systems for ships. As known very well, water is a critical resource on ships, especially the ones serving quite a large number of passengers (Mouchtouri et al., 2012). Both potable and domestic water is needed for purposes such as drinking, food preparation, cleaning, hygiene, and so on. Therefore, water supply systems on ships should be able to meet required water quality and quantity. In this study, therefore, RO system capability under different conditions together with cost analysis was examined on a cruise ship.

\section{Materials and methods}

The purpose of this paper was to make a study related to obtain drinking water with an integrated reverse osmosis system from seawaters having different physical and chemical properties. The integrated system used in this study consisted of sand filter, microfilter membrane and mineralization filter units. In this context, the main goal of this study was to determine the ideal conditions by calculating the efficiency of the integrated system.

The parameters to be followed with in this study were temperature, salinity, $\mathrm{pH}$, efficiency and cost effectiveness. The results were evaluated and compared with each other, by examining samples taken from Black Sea, Aegean Sea and Mediterranean Sea which are circulating Turkey.

\subsection{Experimental procedure}

The integrated system, which has a capacity of $30 \mathrm{~m}^{3} /$ day, was in use in a small sized cruise ship. Figure 1 shows a schematic representation of the system.

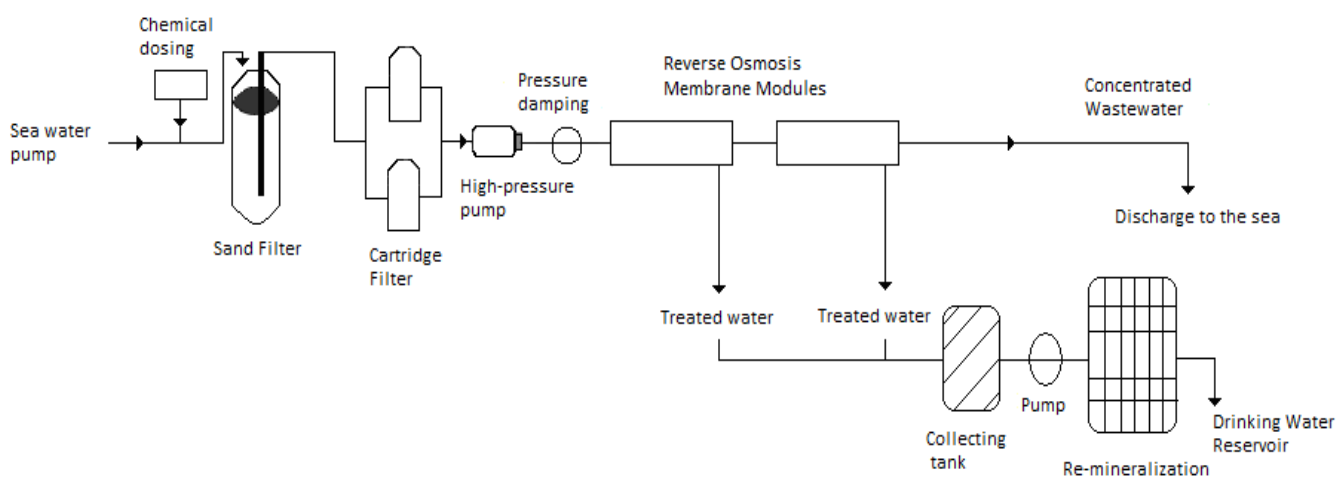

Figure 1. Experimental set-up

The system withdraws the water 3 meters below the sea surface by means of a pump operating with a 5 $\mathrm{m}^{3}$ /hour flowrate. The chemical dosing was made to the system at the water inlet point using a doser (Drew IPD-11-363). Chemical dosing of $0.8 \mathrm{l} / \mathrm{day}$ was made to ensure the stability of calcium sulphate, calcium carbonate, phosphate and barium sulphate concentrations. After chemical dosing, the water is steered through a quartz/hydroantrasit sand filter (Multi-Media Filter) to remove large particles. After the filtration step, sea water reaches the cartridge filters. The cartridge filters, which have $5 \mu$ of particle size, 
were placed parallel to each other. The water from cartridge filters enters into high pressure pump (CatPumps, model 2530) which has a capacity of $5 \mathrm{~m}^{3} / \mathrm{h}$. The maximum operating pressure was 63 bars. The pressure damper was located at the high-pressure pump outlet. The purpose of this damper is to protect membrane filters against unexpected pressure drops. The pressurized water was then introduced to the RO membranes. Two separate reverse osmosis membrane units were used in the system. Features of membrane module can be found in Table 1. Each unit had two membrane filters. Spiral-wound membranes were used in the RO system. Treated water in the membranes was taken to the collection tank through a pipe. The remaining concentrate was given back to sea media. A vertical centrifugal electric pump with a capacity of $1200 \mathrm{l} / \mathrm{h}$ (Lowara) was used to pump drinking water to the water distribution system after re-mineralization using marble and carbon sand filter.

Table 1. Membrane module characteristics

\begin{tabular}{ll}
\hline Manufacturer & Hydranautics SWC3+ \\
\hline Type & Thin Film Composite Polyamide \\
Outer diameter & $8^{\prime \prime}$ \\
Length & $40^{\prime \prime}$ \\
Feed water pH range & $3-10$ \\
Salt removal rate & $\% 99.8$ \\
Polymer Membrane & Composite Polyamide \\
Membrane Area & $400 \mathrm{ft}^{2}$ \\
Maximum Pressure & $8.27 \mathrm{kPa}$ \\
Maximum Operating Temperature & $45^{\circ} \mathrm{C}$ \\
Maximum Feed Water SDI value & 5.0 \\
\hline
\end{tabular}

\subsection{Analytical methods}

Temperature and salinity of samples were measured by related sensors available on the system (Signet, model GF+). Electrical conductivity of samples was measured with Myron L conductivity meter. Barium $\left(\mathrm{Ba}^{2+}\right)$, calcium $\left(\mathrm{Ca}^{2+}\right)$, iron $\left(\mathrm{Fe}^{3+}\right)$, potassium $\left(\mathrm{K}^{+}\right)$, magnesium $\left(\mathrm{Mg}^{2+}\right)$, manganese $\left(\mathrm{Mn}^{2+}\right)$, sodium $\left(\mathrm{Na}^{+}\right)$, strontium $\left(\mathrm{Sr}^{2+}\right)$ concentrations were measured by using an optical emission spectrometer (Perkin Elmer OPT 7000) and a flame atomic adsorption spectrometer (Perkin Elmer AAS 1100). Total dissolved solids (TDS) analyses were performed by the procedures described in the Standard Methods (APHA, 2005). Energy consumption was measured using an ampermeter (Clamp Meter True RMS).

\section{Results and discussions}

The drinking and potable water from different sea water samples were obtained using an integrated reverse osmosis system on a small sized cruise ship, and the cost analysis of the system was performed. The results obtained are presented in the following sections.

\subsection{Seawater characterization}

In this study, seawater samples were taken from 10 separate points. The sampling operation was carried out between October 2009 and May 2010. Detailed information about these samples was presented in Table 2 and the sampling points were presented in Figure 2. The collected samples were kept at $+4{ }^{\circ} \mathrm{C}$ prior to analysis in dark. The characterization results of the seawater samples can be seen in Table 3 .

\section{2. $R O$ system assessment}

According to the World Health Organization (WHO) drinking water standards, the parameters to be analysed were determined and the obtained results were presented in Table 4 . It was seen that the results obtained are all under the defined standards for drinking water set by the WHO (1997).

Salt removal efficiency (Rs) of the system was calculated using Eq. 1 and the efficiencies for all samples were found to be $99.99 \%$. 


$$
R_{s}=\left(1-\left(\frac{C_{p}}{C_{f}}\right)\right) \times 100
$$

where $C_{p}$ is the treated water concentration and $C_{f}$ is the feed water concentration.

Table 2. Location information of the samples

\begin{tabular}{|c|c|c|c|}
\hline No & Name & Coordinate & Seawater Temperature $\left({ }^{\circ} \mathrm{C}\right)$ \\
\hline 1 & Marmaris & $\begin{array}{c}36^{\circ} 37^{\prime} 50^{\prime \prime} \text { Northern } \\
28^{\circ} 26^{\prime} 00^{\prime \prime} \text { Eastern }\end{array}$ & 26.5 \\
\hline 2 & Canakkale & $\begin{array}{c}39^{\circ} 18^{\prime} 50^{\prime \prime} \text { Northern } \\
24^{\circ} 42^{\prime} 50^{\prime \prime} \text { Eastern }\end{array}$ & 16.1 \\
\hline 3 & Canakkale & $\begin{array}{c}39^{\circ} 31^{\prime} 00^{\prime \prime} \text { Northern } \\
24^{\circ} 45^{\prime} 50^{\prime \prime} \text { Eastern }\end{array}$ & 19.1 \\
\hline 4 & Sile & $\begin{array}{l}41^{\circ} 16^{\prime} 50^{\prime \prime} \text { Northern } \\
29^{\circ} 37^{\prime} 50^{\prime \prime} \text { Eastern }\end{array}$ & 9.1 \\
\hline 5 & Eregli & $\begin{array}{c}41^{\circ} 22^{\prime} 00^{\prime \prime} \text { Northern } \\
31^{\circ} 24^{\prime} 50^{\prime \prime} \text { Eastern }\end{array}$ & 9.4 \\
\hline 6 & Kefken & $\begin{array}{c}41^{\circ} 42^{\prime} 50^{\prime \prime} \text { Northern } \\
30^{\circ} 17^{\prime} 00^{\prime \prime} \text { Eastern }\end{array}$ & 11.3 \\
\hline 7 & Samsun & $\begin{array}{c}41^{\circ} 49^{\prime} 50^{\prime \prime} \text { Northern } \\
36^{\circ} 23^{\prime} 00^{\prime \prime} \text { Eastern }\end{array}$ & 10.4 \\
\hline 8 & Sinop & $\begin{array}{c}43^{\circ} 02^{\prime} 50^{\prime \prime} \text { Northern } \\
35^{\circ} 14^{\prime} 00^{\prime \prime} \text { Eastern }\end{array}$ & 11.0 \\
\hline 9 & Trabzon & $\begin{array}{c}42^{\circ} 00^{\prime} 50^{\prime \prime} \text { Northern } \\
39^{\circ} 40^{\prime} 00^{\prime \prime} \text { Eastern }\end{array}$ & 16.0 \\
\hline 10 & Giresun & $\begin{array}{c}41^{\circ} 15^{\prime} 50^{\prime \prime} \text { Northern } \\
38^{\circ} 26^{\prime} 00^{\prime \prime} \text { Eastern }\end{array}$ & 18.6 \\
\hline
\end{tabular}

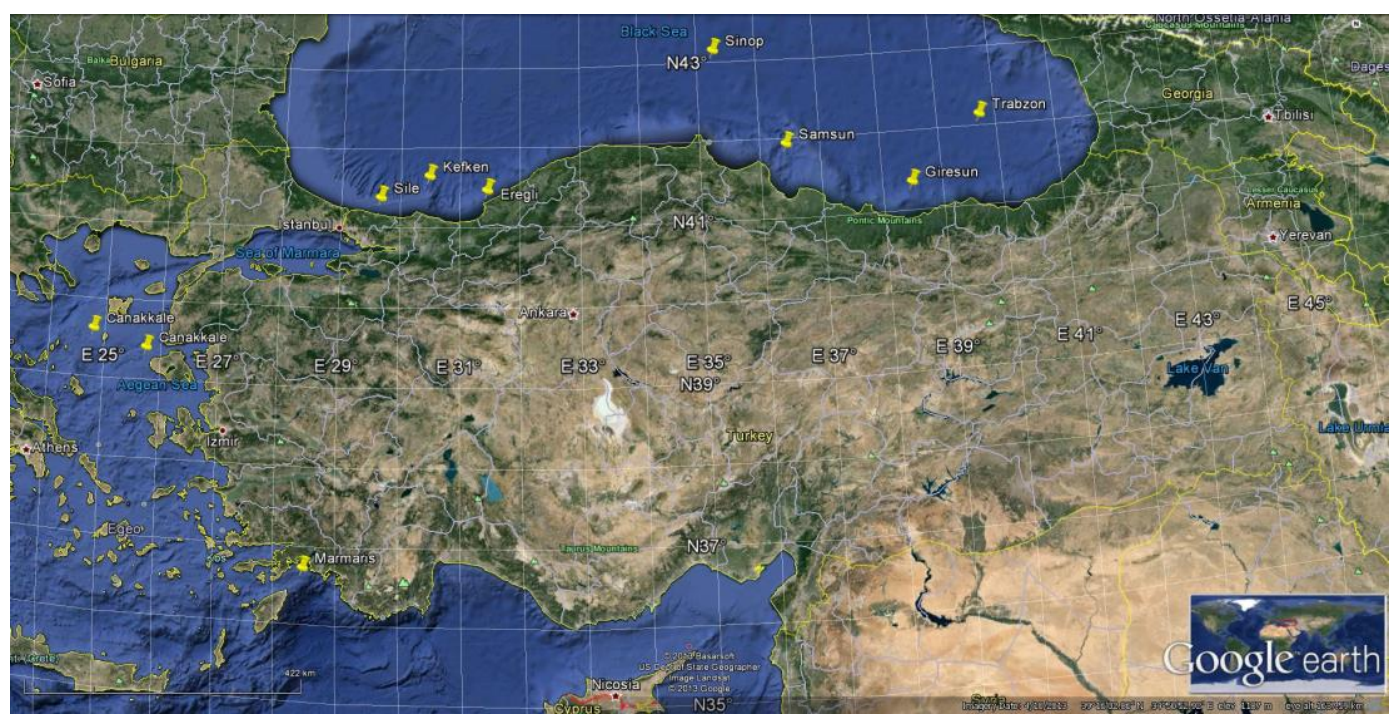

Figure 2. The map of sample sites

In-situ measurements were conducted for parameters such as temperature, TDS, $\mathrm{pH}$ and conductivity analyses. It was observed that the temperature change did not affect the system. According to the analytical analysis results, barium $\left(\mathrm{Ba}^{2+}\right)$ and iron $\left(\mathrm{Fe}^{3+}\right)$ was not found in the inlet water and it was observed that the removal rate of all the analyzed elements were quite high. The removal efficiencies, the applied pressure and the energy consumption results were presented in Table 5 . The removal 
efficiencies were calculated after running the system at least one hour that is, after producing 1200 liters of purified water.

As can be seen from Table 5, the minimum and maximum removal efficiencies of chemical parameters for different sample points did not show great differences. The lowest removal efficiency was found with the sample taken from Kefken-Black Sea (No.6) for manganese $\left(\mathrm{Mn}^{2+}\right)$ element and the highest removal efficiencies were found in all sample points for Strontium $\left(\mathrm{Sr}^{2+}\right)$ element.

Table 3. Influent characterization

\begin{tabular}{|c|c|c|c|c|c|c|c|c|c|c|}
\hline \multicolumn{11}{|l|}{ Sample Number } \\
\hline & 1 & 2 & 3 & 4 & 5 & 6 & 7 & 8 & 9 & 10 \\
\hline & & & & & & & & & & \\
\hline Salinity $\left(\left.\sigma\right|^{-1}\right)$ & & & & & & & & & & \\
\hline Salinity $\left(\mathrm{g} \mathrm{l}^{-1}\right)$ & 43.21 & 37.69 & 38.76 & 20.22 & 19.25 & 18.63 & 19.76 & 19.48 & 19.84 & 20.00 \\
\hline Barium (mg l-1) & 0 & 0 & 0 & 0 & 0 & 0 & 0 & 0 & 0 & 0 \\
\hline Calcium (mg l-1) & 962.1 & 447.6 & 485.4 & 242.8 & 217.1 & 234.6 & 237.6 & 235.5 & 254.0 & 233.9 \\
\hline Iron $\left(\mathrm{mg} \mathrm{l}^{-1}\right)$ & 0 & 0 & 0 & 0 & 0 & 0 & 0 & 0 & 0 & 0 \\
\hline Potassium (mg l-1) & 368.8 & 245.4 & 284.6 & 222.9 & 243.9 & 224.7 & 213.9 & 205.5 & 242.1 & 219.1 \\
\hline Magnesium $\left(\mathrm{mg} \mathrm{l}^{-1}\right)$ & 714.2 & 810.4 & 842.0 & 671.7 & 563.6 & 644.6 & 656.2 & 632.2 & 739.1 & 666.2 \\
\hline Manganese $\left(\mathrm{mg} \mathrm{l}^{-1}\right)$ & 4.4 & 4.1 & 4.0 & 3.6 & 3.5 & 3.4 & 3.5 & 3.6 & 3.5 & 3.7 \\
\hline Sodium $\left(\mathrm{mg} \mathrm{l}^{-1}\right)$ & 7.580 & 5.460 & 5.840 & 630 & 2.240 & 920 & 960 & 1.010 & 950 & 910 \\
\hline Strontium $\left(\mathrm{mg} \mathrm{l}^{-1}\right)$ & 6.4 & 4.8 & 5.3 & 3.9 & 3.7 & 3.6 & 3.7 & 3.7 & 3.7 & 3.7 \\
\hline
\end{tabular}

Table 4. The results of effluent analysis

\begin{tabular}{|c|c|c|c|c|c|c|c|c|c|c|}
\hline Sample number & 1 & 2 & 3 & 4 & 5 & 6 & 7 & 8 & 9 & 10 \\
\hline \multicolumn{11}{|l|}{ Parameter } \\
\hline $\mathrm{pH}^{*}$ & 7.00 & 6.80 & 6.95 & 6.45 & 6.17 & 6.55 & 6.46 & 6.42 & 6.42 & 6.20 \\
\hline Salinity ${ }^{*}\left(\mathrm{~g}^{-1}\right)$ & 2.1 & 1.0 & 1.4 & 0.3 & 0.4 & 0.4 & 0.4 & 0.4 & 0.5 & 0.6 \\
\hline Conductivity $\left(\mu \mathrm{sm}^{-1}\right)^{*}$ & 560 & 280 & 340 & 140 & 150 & 120 & 120 & 120 & 160 & 160 \\
\hline Barium (mg l-1) & 0 & 0 & 0 & 0 & 0 & 0 & 0 & 0 & 0 & 0 \\
\hline Calcium (mg $\left.\left.\right|^{-1}\right)$ & 0.512 & 0.426 & 0.462 & 0.374 & 0.182 & 0.170 & 0.164 & 0.251 & 0.249 & 0.377 \\
\hline Iron $\left(\mathrm{mg} \mathrm{l}^{-1}\right)$ & 0 & 0 & 0 & 0 & 0 & 0 & 0 & 0 & 0 & 0 \\
\hline Potassium $\left(\mathrm{mg} \mathrm{l}^{-1}\right)$ & 1.942 & 1.655 & 1.744 & 1.190 & 1.176 & 1.167 & 1.199 & 1.193 & 1.355 & 1.553 \\
\hline Magnesium $\left(\mathrm{mg} \mathrm{l}^{-1}\right)$ & 1.002 & 0.698 & 0.742 & 0.290 & 0.290 & 0.247 & 0.292 & 0.287 & 0.327 & 0.657 \\
\hline Manganese $\left(\mathrm{mg} \mathrm{l}^{-1}\right)$ & 0.080 & 0.074 & 0.074 & 0.070 & 0.066 & 0.066 & 0.066 & 0.066 & 0.067 & 0.066 \\
\hline Sodium $\left(\mathrm{mg} \mathrm{l}^{-1}\right)$ & 5.2 & 3.9 & 4.2 & 1.1 & 0.6 & 1.1 & 1.3 & 1.2 & 1.9 & 2.6 \\
\hline Strontium $\left(\mathrm{mg} \mathrm{l}^{-1}\right)$ & 0 & 0 & 0 & 0 & 0 & 0 & 0 & 0 & 0 & 0 \\
\hline
\end{tabular}

* These values were obtained from the treatment system which produced 1200 liters water per hour

\subsection{Operational cost analysis}

As known, desalination costs are not difficult to assess, however, total costs may vary dramatically from one facility to another. Therefore, it can be said that this is a challenging issue due to lack of data consistency (Lapuente, 2012). Thus, a part of this study was allocated for cost evaluation of the system. The total cost calculations were carried out taking into consideration the initial investment cost and the operating costs. All costs were given as American Dollars (USD) and the inflation rate was ignored. The system's energy cost schedule was shown in Table 6 and the total costs were presented in Table 7. Distribution of the costs among the samples with different physical and chemical properties was presented in Table 8. As can be seen from Table 8, the total costs consisted of the initial investment cost, energy, membrane, cartridge filter, sand filter, chemical, membrane cleaning, hardening filter, maintenance and services. 
Table 5. The obtained removal efficiency, the pressure and the energy consumption results

\begin{tabular}{|c|c|c|c|c|c|c|}
\hline Parameter & $\begin{array}{c}\text { Min. } \\
\text { Removal } \\
\text { Efficiency (\%) }\end{array}$ & $\begin{array}{c}\text { Max. } \\
\text { Removal } \\
\text { Efficiency (\%) }\end{array}$ & $\begin{array}{l}\text { Pressure, bar } \\
\text { (for min. } \\
\text { Removal } \\
\text { efficiency) }\end{array}$ & $\begin{array}{c}\text { Pressure, bar } \\
\text { (for max. } \\
\text { Removal } \\
\text { efficiency) }\end{array}$ & $\begin{array}{c}\text { Consumption } \\
\mathrm{kW} / \mathrm{h} \\
\text { (for min. } \\
\text { Removal } \\
\text { efficiency) }\end{array}$ & $\begin{array}{c}\text { Consumptio } \\
\text { nkW/h } \\
\text { for max. } \\
\text { Removal } \\
\text { efficiency) }\end{array}$ \\
\hline Calcium & \%99.83 (10) & \%99.92 (6) & 22 & 26 & 10.18 & 10.48 \\
\hline Potassium & \%99.29 (10) & \%99.51 (5) & 22 & 26 & 10.18 & 10.48 \\
\hline Magnesium & \%99.78 (3) & \% $99.96(6)$ & 45 & 26 & 12.25 & 10.48 \\
\hline Manganese & \%98.05 (6) & \%98.21 (10) & 26 & 22 & 10.48 & 10.18 \\
\hline Sodium & \%99.71 (10) & \%99.97 (5) & 22 & 26 & 10.18 & 10.48 \\
\hline Strontium & $\% 100$ & \%100 & 46 & 28 & 12.37 & 10.66 \\
\hline
\end{tabular}

The value given in parentheses indicates the sample number.

Table 6. The cost of energy

\begin{tabular}{ccccc}
\hline Sample Number & $\begin{array}{c}\text { Consumption of } \\
\text { energy }(\mathrm{kW}-\mathrm{h})\end{array}$ & $\begin{array}{c}\text { Consumption of } \\
\text { diesel (l diesel/h) }\end{array}$ & Cost (USD/h) & $\begin{array}{c}\text { Annual Total } \\
\text { Energy Cost (USD) }\end{array}$ \\
\hline 1 & 12.37 & 2.20 & 2.20 & $19,272.0$ \\
2 & 12.01 & 2.14 & 2.14 & $18,746.4$ \\
3 & 12.25 & 2.18 & 2.18 & $19,096.8$ \\
4 & 10.66 & 1.90 & 1.90 & $16,644.0$ \\
5 & 10.48 & 1.87 & 1.87 & $16,381.2$ \\
6 & 10.48 & 1.87 & 1.87 & $16,381.2$ \\
7 & 10.54 & 1.88 & 1.88 & $16,468.8$ \\
8 & 10.48 & 1.87 & 1.87 & $16,381.2$ \\
9 & 10.18 & 1.81 & 1.81 & $15,855.6$ \\
10 & 10.18 & 1.81 & 1.81 & $15,855.6$ \\
\hline
\end{tabular}

Table 7. The total cost for all sample points, and the cost per $\mathrm{m}^{3}$ of treated water

\begin{tabular}{ccc}
\hline Sample Number & Total Annual Cost (USD) & Cost $\left(\right.$ USD m $\left.{ }^{-3}\right)$ \\
\hline 1 & $29,941.44$ & 2.73 \\
2 & $28,343.24$ & 2.58 \\
3 & $28,693.64$ & 2.62 \\
4 & $25,597.24$ & 2.33 \\
5 & $25,334.44$ & 2.31 \\
6 & $25,334.44$ & 2.31 \\
7 & $25,422.04$ & 2.32 \\
8 & $25,334.44$ & 2.31 \\
9 & $24,808.84$ & 2.26 \\
10 & $24,808.84$ & 2.26 \\
\hline
\end{tabular}

As seen in Table 8, the largest contribution to the total cost is due to energy expense, as expected. This was followed by the membrane replacement, maintenance and service costs. It was also observed that the expense of supplies used for chemical cleaning was found to be $10 \%$ of the total cost. It should be noted that all the cost analysis considered that the system is running constantly throughout the year.

Table 8. Distribution of the costs

\begin{tabular}{lccc}
\hline \multirow{2}{*}{ Cost Source } & Mediterranean Sea & Aegean Sea & Black Sea \\
& $(\%)$ & $(\%)$ & 66 \\
\hline Energy & 65 & 11 & 10 \\
Membrane replacement & 14 & 9 & 11 \\
Chemical cost & 9 & 3 & 3 \\
Filter Renewal (Cartridge, Hardening and Sand Filter) & 2 & 11 & 12 \\
Maintenance and Service & 10 & & \\
\hline
\end{tabular}




\section{Conclusions}

In this study, sea water samples from 10 different points from offshore of the Black Sea, the Aegean Sea and the Mediterranean Sea were collected for determining the treatment efficiency and cost analysis of the established integrated reverse osmosis system to satisfy drinking and potable water needs of a small sized cruise ship. The parameters such as temperature, total dissolved solids, $\mathrm{pH}$ and conductivity were measured in-situ; the other parameters were analyzed in the laboratory. It was seen from the results that the temperature difference $\left(10{ }^{\circ} \mathrm{C}\right.$ and $\left.26^{\circ} \mathrm{C}\right)$ was negligible. Salt removal efficiency of the system was calculated to be $99.99 \%$ for all the samples studied. Therefore, it can be said that the system is stable even for high salt concentrations of the Mediterranean Sea. The results of chemical analysis showed that the parameters measured were far below compared to the drinking water standards set by the World Health Organization. This revealed that the used system is capable of meeting the needs of the drinking and potable water and it can be operated in different seas.

The second evaluation within this study focused on examining the system in terms of cost. When examined in terms of operating costs, it was seen that with increasing salinity of the sea water, the service life of the membrane becomes shorter and the cost increases accordingly. Similarly, life of the membranes in the system varies according to the concentrations of total dissolved solids in seawater. Although the membrane filters used in the system were not replaced during the study, looking at the performance of the system over the years, it was concluded that the membranes should be replaced once in every 3 years for the Mediterranean, every 4 years for the Aegean Sea and every 5 years for the Black Sea. It was determined that the highest cost was due to the energy consumption when the operating costs were examined. Exchange of membranes for the waters of the Mediterranean emerges as the second largest source of cost. This was followed by the cost of maintenance and service.

The cost analysis results showed that the resulting water was more costly compared to water supply costs on land, as expected. At this point, one should evaluate alternative energy sources, such as solar, wind or wave energy for seawater desalination.

\section{References}

Al-Sheikh A.H.H. (1997), Seawater reverse osmosis pretreatment with an emphasis on the Jeddah Plant operating experience, Desalination, 110, 1-2, 183-192.

APHA (2005), Standard Methods for the Examination of Water and Wastewater, 21st ed., American Public Health Association, Washington DC.

Bou-Hamad S., Abdel-Jawad M., Ebrahim S., Al-Mansour M. and Al-Hijji A. (1997), Performance evaluation of three different pretreatment systems for seawater reverse osmosis technique, Desalination, 110, 1-2, 85-91.

Durham B. and Walton A. (1999), Membrane pretreatment of reverse osmosis: long-term experience on difficult waters, Desalination, 122, 2, 157-170.

Fritzmann C., Löwenberg J., Wintgens T. and Melin T. (2007), State-of-the-art of reverse osmosis desalination, Desalination, 216, 1-3, 1-76.

Greenlee L.F., Lawler D.F., Freeman B.D., Marrot B. and Moulin P. (2009), Reverse osmosis desalination: water sources, technology, and today's challenges, Water Resources, 43(9), 2317-2348.

Khawaji A.D., Kutubkhanah I.K. and Wie J. (2008), Advances in seawater desalination Technologies, Desalination, 221, 47-69.

Lapuente E. (2012), Full cost in desalination. A case study of the Segura River Basin, Desalination, 300, 40-45.

Misdan N., Lau W.J. and Ismail A.F. (2012), Seawater Reverse Osmosis (SWRO) desalination by thin-film composite membrane - Current development, challenges and future prospects, Desalination, 287, 228-237.

Moran Y., Schreiber E., Skelly J. and Volpe D. (2010), Green Reverse Osmosis Pretreatment for Shipboard Desalination, Faculty of Worcester Polytechnic Institute, Project Number: JYP-0901.

Mouchtouri V.A., Bartlett C.L.R., Diskin A. and Hadjichristodoulou C. (2012), Water Safety Plan on cruise ships: A promising tool to prevent waterborne diseases, Science of the Total Environment, 429, 199-205. 
Shaffer D.L., Yip N.Y., Gilron J. and Elimelech M. (2012), Seawater desalination for agriculture by integrated forward and reverse osmosis: Improved product water quality for potentially less energy, Journal of Membrane Science, 415-416(1), 1-8.

The World Health Organization (WHO) (1997), Guidelines for Drinking Water Quality, Geneva. 